\title{
THE ASSESSMENT OF PHYSICAL FITNESS*
}

\author{
By Prof. David Burns
}

$\mathrm{T}$ ESTS which have been used to assess fitness fall into three classes: (1) somatometric; (2) physiological ; (3) psychological.

\section{SOMATOMETRIC TESTS}

The search for a relationship between the configuration of the body and physical fitness has been pursued since the time of Hippocrates. 'Such a relationship is elusive, and because of the complexity of body build and the scarcity of strictly comparable measurements, most of the findings lack validity.

It was natural, at first, to consider stature as an index of robustness. The tall man with a long reach was better able to hold his own in hand-tohand fighting. Even to-day, height is taken into account in selecting recruits for the services and the police. The tall applicant, too, has generally a better chance of getting engaged in commerce and industry than his shorter competitor. Length, especially length of leg, is not merely an indication of genetic constitution but also of a late incidence of maturity. Chest girth in relation to size of body, at first sight, appears to have at least a probable relationship to fitness, but Gould (I864), who carried out a thorough statistical survey of the manhood of the American nation during the progress of the Civil War, had grave doubts as to the validity of chest measurements for this purpose. Hutchinson showed clearly that the circumference of the chest is no measure of vital capacity, endurance or even of muscular strength, nor is there any evidence that it bears any relationship to the state of general health.

Criteria of Fitness. Since the introduction by McLaren of systematic somatometric measurements as part of the routine of physical education, there has arisen a host of indexes, of which perhaps the best known are Von Pirquet's Pelidisi and Franzen's A.C.H. indexes.

In general, chests may be divided into three types : the wine-glass-wide shoulders and narrow hips; the test-tube-both measurements small; and the barrel with broad shoulders and wide hips. Persons of the test-tube type are often abdominal breathers, that is, they obtain their tidal air by contracting the diaphragm and displacing the viscera into a relaxed abdominal wall. Experiment

\footnotetext{
* From the presidential address to Section I (Physiology) of the British Association, Dundee.
}

shows that they have a larger effective vital capacity than the others and are generally more amenable to training. On the other hand, all three types are normal and are equally fitted, so far as bodily relations go, for the battle of life. One cannot mark down any type as fundamentally healthier than the others. The test-tube type is more prone to tuberculosis but less prone to rheumatism, diabetes and arterio-sclerosis than the barrel.

None of these indexes is valid as a measure of fitness, even when due allowance is made for race, type of body build, sex or occupation.

\section{Physiological Tests}

Fitness is functional. The body must be tested at work. The measurement of vital capacity is generally classed as physiological although it is not strictly functional. This measurement, a common routine practice, has no real significance. The amount of air that a person can contain in his lungs is a measure of chest capacity and of the tone of the respiratory musculature, but the person with an extra large vital capacity has no advantage over one who has quite a small capacity provided that he has sufficient.

There is a prevalent error that so-called deepbreathing exercises where the shoulders are forced back and the chest brought forwards and upwards increase vital capacity. Actually, by fixing the pectoral muscles and stretching the abdominal wall, these procedures prevent full inspiration and expiration and increase the volume of air left in the lungs (residual air). Chest breathers have about the same vital capacity, whether taken at ease or on the stretch, while 'deep breathing' may reduce the vital capacity of abdominal breathers by about 30 per cent. The value of deep. breathing exercise lies in its effect on the filling of the heart and so on the maintenance of cardiac efficiency.

One is on surer ground when using the various breath-holding tests either per se or against pressure. The former is a measure of the alkali reserve of the blood and of the determination of the subject not to give in. The $40 \cdot \mathrm{mm}$. test brings out both these qualities and, in addition, is a severe test of muscular strength and control.

Bainbridge and Darrson quote the results of experiments which show clearly that fit and/or 
skilled men carry out physical work with but a slight increase in lactic acid, while the unfit, under the same conditions, have a higher blood-lactic acid content. That is, the reserve of alkali in the blood of the fit is large enough to cope with all or most of the acid released as a result of muscular exercise. Recruits have on the average 5 per cent less available base than the soldiers. Dawson states that three months' systematic physical education can raise the amount of available base by about 10 per cent.

Similar 'fitnesses' associated with other groups of muscles can be tested by various dynamometers. Martin introduced a new procedure into this type of test. Instead of measuring the strength of a subject's active pull on a dynamometer, he applied the pulling force to groups of muscles and recorded the force necessary to break down the subject's active resistance to the movement of the musclegroup under test. The summation of a series of selected groups of muscles thus gives an indication of the total muscular strength of that individual as well as of his determination to resist. It gives no measure of his skill or of his economy of movement. It may be asked: Is muscular strength plus determination an adequate measure of general fitness?

Limiting Factor of Efficiency. It is well known that the limiting factor, the factor which determines whether muscular strength can be exerted to its full extent, the factor which overrides the will to do, is vaso-cardiac efficiency. Goodall recognized this when he published his efficiency tests. If, after a measured amount of exercise, the pulse rate and blood pressure come back to normal in a specified time, depending on the severity of the exertion, then the subject of the test is fit.

With a healthy heart, cardiac efficiency ultimately depends on the venous filling. A pump without a well may be a thing of beauty, the last word in mechanical efficiency, but its usefulness is non-existent. About 85 per cent of the total volume of the blood is in the capillaries and veins under normal conditions. Under these conditions, all capillaries are not patent at any one time. The splanchnic viscera, and particularly the liver and the spleen with their rich venous supply, are capable of retaining much larger quantities of blood than they do. If, for any reason, more capillaries open up at the same time and the splanchnic reservoir becomes filled with blood, the amount freely circulating, the amount necessary to fill the receiving chambers of the heart, becomes inadequate. The controlling factor in the distribution of blood, in maintaining an effective circulation, lies mainly in the tone of muscle-cardiac, visceral and, last but by no means least, ordinary skeletal muscle.
The venous return is also aided by the rhythmic alterations of intra-thoracic pressure with the phases of the respiratory act. It is, however, only in abdominal breathing that the respiratory act aids the return of blood to the heart. These alternating pushes and pulls, produced by muscular action dependent on the tone of the diaphragm and muscles of the abdominal wall, have a minor effect on venous return in comparison with the constant tonic push of muscle in general. During exercise, more capillaries in muscle become patent and, if muscle is in good tone, more blood is put under tissue pressure. On the other hand, if tone is at a low level, blood filling the capillaries is not pressed out, congestion appears and the heart fails through lack of blood. The fit person whose heart is able so to increase its output per unit of time that adequate blood is supplied to active tissues to meet their increased needs, must have a higher value of muscle tone than the unfit. Experiment shows that healthy young men have a tone in their relaxed left biceps muscle which is capable of withstanding a pressure of $60-90 \mathrm{~mm}$. of water; while patients in-bed have an intra-muscular pressure of about $50 \mathrm{~mm}$. of water.

Intra-muscular pressure is markedly increased when muscle contracts, so that, as the fibres in muscle shorten intermittently during exercise, the blood is expelled from the venules in the muscles intermittently. This pulsation plays an important part in maintaining the tone of the vessel walls. The hæmostasis produced by immobile standing, shown by swelling of the legs in unfit persons, may be prevented by almost imperceptible voluntary twitches of the calf muscles or even by movements of the toes. Standing rigidly at attention is a severe test of the efficiency of the mechanisms responsible for the venous return to the heart.

Muscular tone is dependent on many factorsadequate blood supply, absence of excess of fatty upholstery, a regular arrival of motor impulses to the muscle controlled from higher centres and a cooling mechanism nicely co-ordinated to the needs of the moment. It is easy to demonstrato that faulty heat loss lowers tone. The avenue by which heat is lost is apparently unimportant, but, unless under the artificial conditions of the laboratory, where even loss by radiation can be made the effective sole method of losing heat, the evaporation of moisture from the skin is the usual limiting factor. Several investigators have shown that the phenomenon known as 'second-wind', by which a runner experiences a sudden relief from the agony of breathlessness and the leaden drag of weary muscles, is accompanied by sweating. When this occurs, alveolar carbon dioxide falls, the urgency of breathlessness fades, the head clears and the muscles act with renewed vigour. 
Measures of Fitness. Three means of measuring fitness are thus indicated, and they are interrelated: $(a)$ Tests of recuperative efficiency. The ability of the cardio-respiratory mechanism to return to normal functioning within a limited time after exertion. (b) The ease of heat loss under specified conditions. (c) The value of muscle tone.

(a) Tests such as Goodall's, Crampton's, Foster's, McCurdy's and Schneider's, which depend on arbitrary scoring for rise of pulse rate, blood-pressure and respiration rate after exercise, and scoring for the length of time for a return to pre-exercise levels, have a very low coefficient of reliability. Schneider's is the best, with $r=0.4$. MIcloy prefers to measure alterations in diastolic pressure and pulse rate on standing erect after lying supine. For this $r$ was between 0.8 and 0.9 in a limited study of healthy and convalescent golfers.

Turner's test, which depends on the cardiovascular reactions during standing absolutely still for 15 minutes, has a coefficient of reliability of above 0.9 for adults but yields anomalous results with boys. In Schneider and Crampton's studies of pre-adolescent boys, the boy proved least fit by all other tests was the sole survivor at the end of 15 minutes' standing (with a pulse pressure of $8 \mathrm{~mm}$. mercury !). The others had either given in or had fainted.

The rate at which the oxygen debt is repaid may be used as an index of physical solvency. The fit subject either pays cash to close the transaction or demands short credit. The percentage of the total debt liquidated during 3 minutes after the cessation of exercise is, in the case of the unfit, about 30 , while the same subject, in condition, may have discharged more than 60 per cent of his debt. The drawback to the employment of tests of recuperative power is the possibility of overstraining the vaso-cardiac mechanism in the unsound.

(b) No large series of experiments has yet been planned to gauge the reliability of this test of efficiency.

(c) The value of muscle tone may be determined in various ways. Coffey, Barnum and Henderson used the knee-jerk as an index of tonus. Even when absolutely uniform strokes of the hammer are applied to the patellar tendon of a co-operating subject, variable degrees of the extent of kick are obtained with successive stimuli. It is a useful method to demonstrate the gross alterations for which these workers used it, but, principally because it requires a trained subject for accurate results, it is not of general utility. The direct reading of intra-muscular pressure is awkward and somewhat unpleasant for the subject. Several attempts have been made to link creatinine excretion with muscle tone.

Noël Paton, in his presidential address to Sec- tion $I$ at Bournemouth in 1919, put forward the suggestion that the maintenance of muscle tone (and hence of physical fitness) depended in part on the presence in tissue-fluid of small quantities of guanidine or its methyl derivative. He showed unequivocally that muscle, either of warm- or cold-blooded animals, increased in tone when minute amounts of the salts of this base were administered. Since then much work has been done to elucidate this problem. Sullivan was able to estimate the urinary guanidines in cases of progressive muscular dystrophy before and during treatment. As the cases improved, under glycortal medication, simple guanidines disappeared from the urine. More recently, Minot has successfully treated patients suffering from this disease by oral administration of guanidine hydrochloride; and Dewar, working in my laboratory, has confirmed this (using the tasteless carbonate). Unfortunately, exhaustive search has failed to find a reliable method for the estimation of urinary or blood guanidine, and so, as a test of tone, the determination of the simple guanidines is, at present, unavailable.

The sympathetic control of muscle tone has been the subject of many investigations and much controversy. There is a wealth of indisputable evidence that the anatomical sympathetic system plays, at best, a minor part in the direct maintenance of muscle tone, and no one now holds the views of Hunter or of Royle. On the other hand, the work of the Orbeli school, amply confirmed by later expcrimenters from other laboratories, points to the influence of adrenergic nerves on the neuromuscular mechanism. This influence is shown more clearly when the action of the vasoconstrictor fibres is removed by poisoning with ergotoxine. This may be taken to mean that the main function of the sympathetic in the maintenance of muscular tone lies in ensuring effective vasodilatation of the muscle capillaries brought about through the so.called 'nutrition reflex'. The fit man, with good muscle tone, soon stops the drain on the blood supply to skin and viscera, while the unfit keeps the pallor of skin for some time and may even show signs of acute digestive upset. One may, therefore, test fitness by estimating the degree (amount $x$ time) of the deprivation of the skin of moving blood.

The responsiveness of the sympathetic arm of the reflex arc depends on the functioning of the cortices of the suprarenal glands. This pair of ductless glands with a long ancestral history is absolutely necessary for life and is affected by any undue strain on the reserves of strength. The will to endure, to keep going on, is mental, but the power to force an unwilling body to obey the order of the mind, to exert its last ounce and not die in the 
last ditch, depends, in the end, on the adequacy of the secretory mechanism of the cortices suprarenales. Animals with grafts of cortical tissues and no medullæ act as normals. Injection of cortical extract to completely adrenalectomized rats restores voluntary activity to an extent depending on the amount of cortin given. Hypertrophy of cortical tissues follows exercise in the rat. "Pos. sibly", says Dill, "one of the effects of training is to increase the secretory activity of the adrenal cortex."

The sequel $x$ of severe muscular exercise under conditions where cooling is inadequate differ only in degree from those of cortical insufficiency, that is, loss of muscle tone, increase of blood potassium and lowering of blood sodium both absolutely and relatively. The loss of tone may be due to imbalance between the metallic ions as well as to exhaustion of cortical supplies, as it may be mirrored in normal subjects by administration of salts of potassium.

\section{Psychological Tests}

The fit man carries on his work and his play without an unpleasant degree of fatigue, and so his industrial output may be taken as a measure of his fitness. The amount of work done or the goodness of the work done depends not only on the physical state of the worker but also on the state of his mind. It is well known that work which is in itself pleasant or leads to pleasure as a more or less remote result is carried out with an efficiency lacking in more formal performances or in forced work. L. Hill, Gillespie and many others have shown that the initial cardiac acceleration followed by peripheral and splanchnic vasoconstriction leading to an increased venous return to the heart with consequent cardiac retardation and increased output is mainly psychical in origin. If the work is uninteresting or the movements passive, these preparatory circulatory changes do not take place and the organism as a whole is thus less fitted to do work. Investigations involving treadmills, stationary running, bicycle ergometers, etc., may thus fail to reveal accurately the efficiency of a subject because of the more or less complete lack of interest of the work once the novelty has worn off. The performance becomes a routine and the efficiency consistent but low. On the cessation of the mental effort, the tone of muscle falls, the peripheral and visceral vasoconstriction passes off and output falls. One of the conclusions, drawn from the results of many exhaustive investigations made in the United States and in Great Britain, is that good sociological conditions are of paramount importance if good work is to be expected. Even apparently trivial improvements in amenities lead to increased output. For example, the average output of relays per hour in the Western Electric factory at Chicago of $\check{5} 5 \cdot 7$ when lunch was provided by the management, rose to $66 \cdot 4$ when the employees supplied their own lunch. This rate was maintained over two periods of 31 weeks (of the observation period) and was a record (Whitehead quoted by Dill). Hitler realized this principle, in theory at least, when he instituted his 'Strength through Joy' movement.

Value of 'Stunt' Tests. Cathcart places great value on the ability to react rapidly and accurately to changes in the environment. Efficiency in this can be tested by presenting the subject with exercises which demand new co-ordinations as well as motor activity with a performance both easy and graceful. This type of test, as outlined by Brace, MrCloy and others, has a coefficient of validity of more than 0.8 .

\section{EXERCISE AND FitNeSS}

What, then, can be said of the effect of exercise in maintaining fitness? The Committee of the Health Section of the League of Nations is rather despondent on this matter. It says, "Up to the present, methods and systems of physical education have not produced any clearly demonstrable effect on the health of the masses, doubtless because the present state of our knowledge is not as yet sufficient to enable us to base them on accurate scientific data" (1938).

Properly designed exercises, carefully controlled, can be used to correct faults of carriage, to eliminate uneconomic muscular actions and fit the mildly dysplastic to take their place without shame among the euplastic. The danger of such excrciso lies in any attempt to create an 'ideal' posture, etc., which has no physiological foundation.

Exercise carried on without strain or undue fatigue keeps the body in tone; and some exercise is considered beneficial to those-engaged in sedentary occupations especially, as it increases the venous return to the heart and prevents stagnation in the blood reservoirs and lower limbs. The group of experts of the Commission on Physical Training were therefore enjoined "to determine the minimum amount of physical training required to ensure the normal health of the individual".

Exercise designed to 'build muscles' beyond the needs of that particular person merely leads to increased food intake, and when, because of age or lack of opportunity, the amount of exercise is decreased, fibrous and fatty degeneration and infiltration takes place. While it may be 'better to have lov'd and lost', it is certainly not better to have exercised and stopped.

Probably the main beneficial result of keep-fit classes and similar movements is the inculcation of a spirit of independence, personal confidence and 
pleasure in performance. Although "the healthy body works in silence" (Carrel), the fit person has a keen sense of the enjoyment to be obtained from suitable exercise. The physiological foundation of the exhilaration resulting from exercise-an exhilaration not entirely due to a decreasing handicap at golf or competitive improvement at other games- would be a suitable and profitable study for ambitious politicians and others.

While it is true that one cannot assess a man's efficiency until his whole life's story has been unrolled (and then it is too late to do anything about it), one should be able to establish norms related to age and sex. The recent Military Service Act provides an occasion for the audit of the nation's young manhood, and, provided suitable tests are applied by properly trained examiners, a beginning will have been made to the collection of facts and figures from which much may be learned.

There is no doubt as to the improvement in mental and physical fitness that results from wise physical training, co-operative effort and good feeding such as that obtained in military camps of the best type. Such training may go far towards reconditioning some of the youth of Great Britain. The American Department of Labour, in a report (1935) on two years' experience of civilian conservation camps, says, "Thousands of actual case records reflect the fact that the C.C.C. men have returned to their homes definitely benefited physically and mentally; their outlook toward the future is brighter, their sense of self-reliance and their ability to adjust themselves to economic conditions is stronger." To this tribute to wise and varied physical, mental and moral education one may add the results of a short experiment in effectively reconditioning a selected number of rejected recruits for the British Army: "My predecessor started a depot for training a limited number of men who were below standard and, as a result, . . .576 of the 600 ... have reached the full standard of fitness" (Right Hon. L. HoreBelisha, Devonport, 1937).

While not in any way detracting from the importance of work of this type on men during late adolescence and early maturity, one may ask why the audit is not made earlier in the course of our national business of turning out citizens-taken early before the debit balance of wasted lives becomes so large that strenuous measures have to be taken to safeguard our interests. No factory the products of which were good, bad and indifferent would exist long before the shareholders were demanding an inquiry and a change of directorship. Our national strength lies in our men and women and not in the machines that they tend or the battleships that they man. To be really great a State must have citizens fit in body and also in mind. "The health of the intelligence and of the affective sense, moral discipline and spiritual development are just as necessary as the health of the body and the prevention of infectious diseases" (Carrel).

To ensure this would cost money, but so does radium. The chief use of this rare element is to prolong the life of the aged; should we not be equally ready to foot a bill which would make young lives more fit to bear hopefully and without undue strain the heavy burden their ancestry has laid on them?

\section{OB ITUARIES}

\section{Mr. H. P. Hollis}

$\mathrm{A}$ STRONOMICAL circles will miss the familiar figure of H. P. Hollis, who died on August 7 at the age of eighty-one years. Hollis was born on January 9,1858 , and was educated at Westminster, from which ho went to Jesus College, Cambridge. Ho took his degree in 1880 and in the following year was ap. pointed to the post of assistant at the Royal $\mathrm{Ob}$. servatory, Greenwich, where he remained for forty years, retiring in 1920. His work at first was connected with the regular astronomical observations with tho transit and altazimuth instruments; but later he took part in the measurement and reduction of solar photographs. Among his various other activities must be mentioned his work in the determination of the difference of longitude between Greenwich and Paris. The reductions of the observations made in 1892 and also in 1901 were carried out under his directions. In 1896 he was promoted to a higher grade and took charge of the work of the Astrographic Chart and Catalogue. A record of his twenty-four years in this department is found in the two volumes which give the positions of the stars as measured on the photographs and also the photographic reproduction of the chart plates, as well as in the two other volumes supplementing these results.

Outside his professional duties at the Royal Observatory, Hollis took a keen interest in astronomy and was always pleased to assist the amateur in his difficulties. For some years he contributed very useful information to the tyro by his letters to the English Mechanic. He was an original member of the British Astronomical Association founded in 1890, and was president during 1908-9. In addition to serving on the Council at various times, he repre- 